\title{
Changes in South African rocky intertidal invertebrate community structure associated with the invasion of the mussel Mytilus galloprovincialis
}

\author{
Tamara B. Robinson ${ }^{1,2, *}$, George M. Branch ${ }^{1}$, Charles L. Griffiths ${ }^{1,2}$, \\ Anesh Govender ${ }^{1}$, Philip A. R. Hockey ${ }^{3}$ \\ ${ }^{1}$ Marine Biology Research Institute, Zoology Department, University of Cape Town, Private Bag X 03 , \\ Rondebosch 7701, South Africa \\ ${ }^{2}$ Centre of Invasion Biology, Zoology Department, University of Cape Town, Private Bag X 03, \\ Rondebosch 7701, South Africa \\ ${ }^{3}$ DST/NRF Centre of Excellence at the Percy FitzPatrick Institute, University of Cape Town, Private Bag X 03 , \\ Rondebosch 7701, South Africa
}

\begin{abstract}
Since the establishment of the alien mussel Mytilus galloprovincialis in South Africa, several authors have studied its interactions with individual indigenous species. However, the broader implications of this invasion on the intertidal zone remain undocumented. This paper analyses the impacts of this mussel on the rocky-shore invertebrate community structure at Marcus Island on the west coast of South Africa. The effects of the invasion were linked to 3 key elements and were not consistently spread across the intertidal zone, but were focused within the mid-to-low shore. Firstly, physical stress in the mid-intertidal zones was ameliorated by the presence of M. galloprovincialis beds. Secondly, habitat complexity was increased where $M$. galloprovincialis replaced bare rock or less complex secondary habitat. Thirdly, habitat became less patchy as mussel beds blanketed the shore. Consequently, invertebrate density and species richness increased substantially, and community composition changed significantly in the mid-shore. Lower on the shore, significant changes in invertebrate community structure were driven by a switch from mono-layered beds of the small indigenous mussel Aulacomya ater to multilayered beds of $M$. galloprovincialis, despite no change in total species richness.
\end{abstract}

KEY WORDS: Alien mussel · Community structure $\cdot$ Marine invasions $\cdot$ Mytilus galloprovincialis Rocky shores

\section{INTRODUCTION}

The spread of alien species is altering the composition of marine communities on a global scale (Ruiz et al. 1999, Mack et al. 2000, Grosholz 2002) and has been identified as a major threat to biodiversity (Occhipinti-Ambrogi \& Savini 2003). Many studies have considered direct interactions between alien and indigenous species (Berman \& Carlton 1991, Byers 2000, Byrnes \& Witman 2003, Bachelet et al. 2004, Le Pape et al. 2004), but relatively little attention has been paid to the impacts of alien species on the biological structure of the communities they invade.

One alien species that has received substantial attention at the level of species-specific effects is the mytilid mussel Mytilus galloprovincialis along the South African coast. As the most abundant and widespread invasive marine species in this region (Robinson et al. 2005), M. galloprovincialis has partially displaced the local mussels Choromytilus meridionalis and Aulacomya ater along the west coast (Hockey \& Van Erkom Schurink 1992), while exhibiting spatial segregation 
with the indigenous mussel Perna perna on the south coast (Robinson et al. 2005). As a consequence of the rapid growth rate, high fecundity and desiccation tolerance of this invasive mussel (Van Erkom Schurink \& Griffiths 1990, Hockey \& Van Erkom Schurink 1992), its arrival resulted in a net upshore shift in the zonation of intertidal mussel beds. Due to extremely high recruitment rates (up to 20000 recruits $\mathrm{m}^{-2}$; Harris et al. 1998), M. galloprovincialis presently dominates primary rock surfaces at the expense of various competitively inferior limpet species (Branch \& Steffani 2004). By excluding the limpet Scutellastra granularis from open rock, M. galloprovincialis has reduced the number of individuals that occur directly on rock, although at the same time it offers the potential of increasing overall $S$. granularis density by providing a favourable settlement and recruitment substratum for juveniles (Griffiths et al. 1992, Hockey \& Van Erkom Schurink 1992). A second limpet species, Scutellastra argenvillei, has also been significantly affected by this invasion, although the strength of the interaction between these 2 species is mediated by wave action (Steffani \& Branch 2003a,b). On exposed shores, $M$. galloprovincialis outcompetes $S$. argenvillei and dominates the primary substratum, while, on semi-exposed shores, the mussel is relatively scarce and $S$. argenvillei maintains dominance in open rock space (Steffani \& Branch 2003a,b).

Besides the biological role of mussels on rocky shores, they also form an important biotic substratum (Seed \& Suchanek 1992). Mussel beds impact surrounding community structure as the highly complex configuration of mussel matrices offers a multitude of microhabitats, which ameliorate fluctuating environmental conditions and provide protection from predation (Gosselin \& Chia 1995). The physical presence of the mussel shells also constitutes a suitable hard substratum for settlement and development of co-occurring species.

Despite substantial work on the ecological impacts of Mytilus galloprovincialis and the known role of mussels as biotic substratum, the impact of this invasion on the intertidal community has not been considered. In an effort to elucidate community impacts of such invasions, this study characterises changes in intertidal invertebrate community composition following invasion of South African rocky shores by M. galloprovincialis.

\section{MATERIALS AND METHODS}

This study took place on the southern shores of Mar-

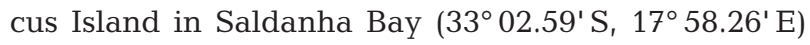
on the west coast of South Africa. The distribution and abundance of intertidal invertebrates was recorded in 1980, before the invasion of Mytilus galloprovincialis was recognised (although this species may have been present in low numbers) and again in 2001, by which time $M$. galloprovincialis was well established and had invaded much of the South African coast (Robinson et al. 2005). In 1980, 7 intertidal zones were identified and sampled. They were (in descending order of tidal height):

(1) The Porphyra zone, consisting of patchy beds of the alga Porphyra capensis.

(2) The Ulva zone, characterised by mixed beds of the algae Ulva capensis and Ulva (=Enteromorpha) linza.

(3) The Granularis zone, dominated by the limpet Scutellastra granularis.

(4) The algal turf zone, covered by a moss-like red algal community dominated by Caulacanthus ustulatus.

(5) The Gigartina zone, characterised by the algae Gigartina radula and Pterosiphonia cloiophylla.

(6) The Aulacomya zone, dominated by the ribbed mussel Aulacomya ater.

(7) The Choromytilus zone, comprising beds of the black mussel Choromytilus meridionalis.

In 1980, 10 to 16 quadrats, each of $0.01 \mathrm{~m}^{2}$, were selected randomly in each zone from within areas of $100 \%$ algal or mussel cover. These quadrats were cleared, and all mobile and sessile invertebrates $>1 \mathrm{~mm}$ in size were counted and identified to species level. In the Granularis zone, where invertebrates tend to be large and sparsely distributed, animals were counted in situ in 27 quadrats of $0.5 \mathrm{~m}^{2}$.

In 2001, the same survey protocol was used, with 2 exceptions. Firstly, Mytilus galloprovincialis had overrun most of the Granularis zone, making it inappropriate to employ the $0.5 \mathrm{~m}^{2}$ quadrats previously used to sample this zone, and $0.01 \mathrm{~m}^{2}$ quadrats were cleared. Secondly, 7 samples were taken per zone. These were randomly, horizontally interspersed between the 1980 samples. To ensure equivalent areas were analysed in 1980 and 2001, in each zone a randomly selected subset of 7 samples from 1980 was compared with the 7 samples taken in 2001. All calculations, except those of rarefaction curves, were conducted using the random sub-sample.

Prior to univariate analyses, data were tested for normality using the Kolmogorov-Smirnov 1-sample test and for homogeneity of variances using Levene's test. All univariate analyses were conducted using STATISTICA for Windows (Version 6), StatSoft Inc. (2004), with $\alpha$ set at 0.05 .

Densities per square metre of mussels and other invertebrates were compared before and after the Mytilus galloprovincialis invasion (1980 versus 2001) using the Mann-Whitney $U$-test. Each intertidal zone was considered separately.

To estimate the sufficiency of our sample size and compare species richness between times in the respective zones, sample-based rarefaction curves (Gotelli \& 
Colwell 2001) and the incidence-based richness estimate Chao 2 (Chao 1987) were calculated using the programme EstimateS (Colwell 2005).

Community composition (based on numerical abundance) was analysed separately for each intertidal zone using multivariate techniques in the PRIMER software package (Plymouth Marine Laboratory) and non-standardised, fourth-root transformed data. ANOSIM was employed to detect significant changes in community structure between 1980 and 2001. SIMPER resolved which species were responsible for these changes. Non-metric multidimensional scaling was used to generate graphic illustrations of the differences between the 1980 and 2001 communities in each zone.

\section{RESULTS}

In 2001, only 6 of the original 7 intertidal zones could be detected. The algal turf zone could no longer be distinguished and thus could not be resampled. Despite the exclusion of this zone from the following analyses, it should be noted that the disappearance of a zone in itself represents a major change in community structure. As the vertical heights of the respective zones were not recorded in 1980, it was not possible to determine if this zone had become dominated by Mytilus galloprovincialis, or if it had been incorporated into the zones previously occurring above or below it.

The densities of the various mussel species in each zone in 1980 and 2001 are shown in Fig. 1. In 1980, Choromytilus meridionalis occurred at relatively low densities of 2000 to $5000 \mathrm{~m}^{-2}$ across most of the shore, except in the Granularis zone and in the algal-dominated zones higher on the shore. The smaller Aulacomya ater attained much higher densities, but was confined to the lower intertidal zone. In 2001, Mytilus galloprovincialis was recorded in all sampling zones, with the exception of the Porphyra zone, and dominated 4 out of 5 of these zones, reaching densities of 2000 to $10000 \mathrm{~m}^{-2}$. In the mid-shore Ulva and Granularis zones, the M. galloprovincialis invasion increased the total number of mussels present, but did not replace those present prior to its invasion. This was, however, not the case in the Aulacomya and Choromytilus zones, where the invasion markedly decreased the densities of indigenous mussel species, particularly A. ater. By 2001, there had been a shift in the distribution and abundance of mussels from the Aulacomya zone to higher up the shore, with all zones except the Aulacomya zone showing an increase in overall mussel density (Fig. 1).

In the Porphyra and Choromytilus zones there were no significant differences in the overall densities of invertebrates between 1980 and 2001 (Mann-Whitney $U$-tests, $\mathrm{p}<0.05$; Fig. 2). In the Ulva and Granularis zones there

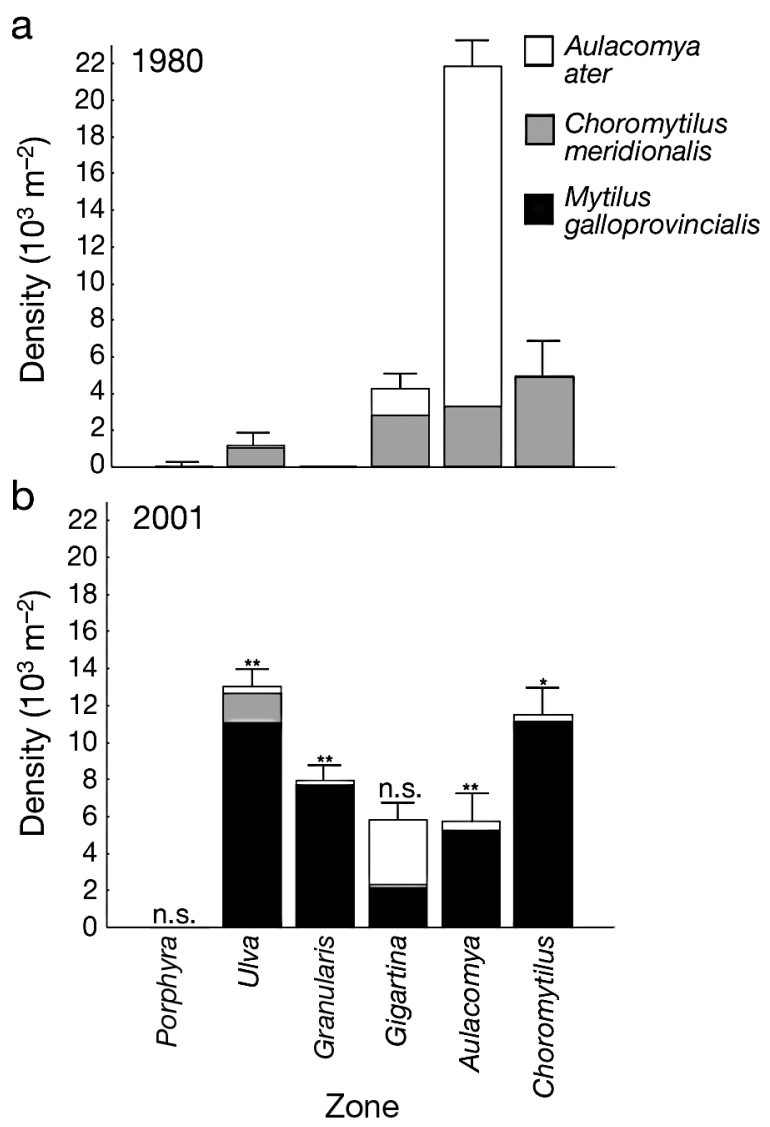

Fig. 1. Mean densities (+SD) of the various mussel species recorded per square metre in each intertidal zone on Marcus Island in 1980 and 2001. Mytilus galloprovincialis may have been present in low numbers in the 1980 survey, but undetected due to misidentification (n.s.: no significant difference in overall mussel densities between years; ${ }^{*} \mathrm{p}<0.05 ;{ }^{* *} \mathrm{p}<0.01$ )

were substantial and significant increases in invertebrate density ( $p<0.01)$, whereas decreases occurred in the Gigartina and Aulacomya zones (respectively, p < 0.05 and $\mathrm{p}<0.01$ ). The increases reflected invasion by Mytilus galloprovincialis of zones that previously supported few mussels. The reduction in invertebrate density in the Gigartina zone was a result of the disappearance of a single gastropod species (Aetoniella nigra), which was common in 1980. The decline in the Aulacomya zone reflected a shift from the typically smaller but abundant Aulacomya ater to larger but less dense M. galloprovincialis and a reduction in crustacean numbers. Except in the Porphyra and Aulacomya zones, there was a dramatic increase in the density of mussels between 1980 and 2001. The most striking increase occurred in the Granularis zone, where mussels were absent in 1980, but, in 2001, occurred at a density of 2660 individuals $\mathrm{m}^{-2}$ (4012 SD). In contrast, there was a marked decrease in density of mussels in the Aulacomya 


\section{a}

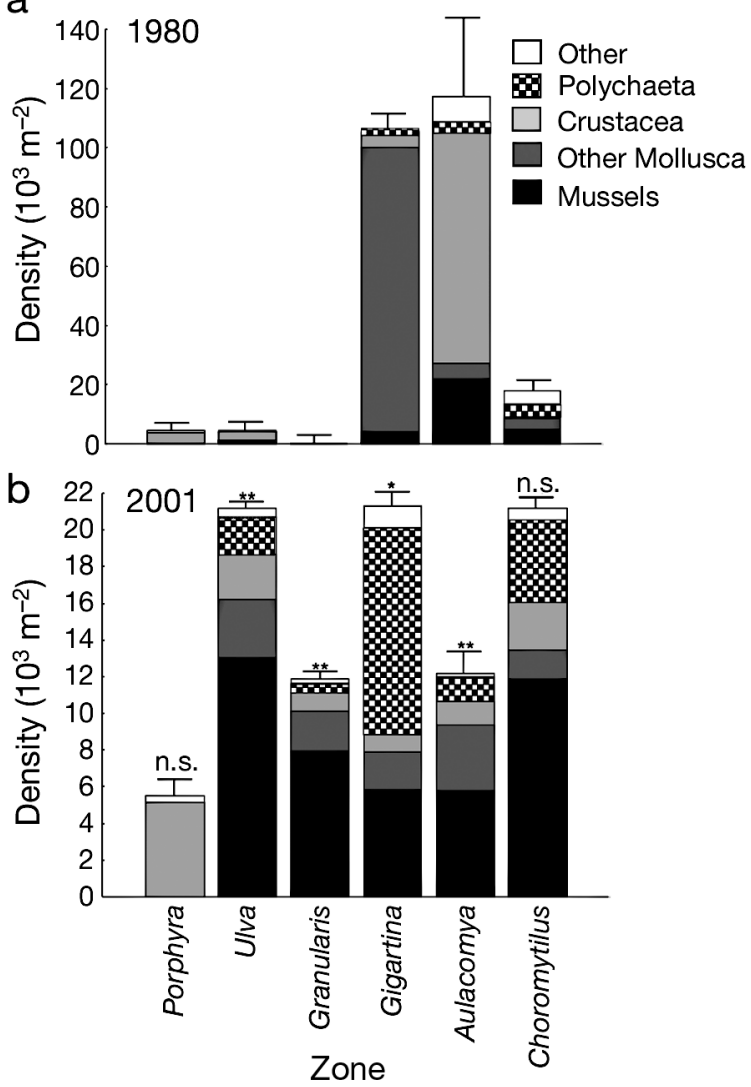

Fig. 2. Mean densities (+SD) of invertebrates recorded per square metre in each zone on Marcus Island in 1980 and 2001, coded by major taxonomic groups. Note the difference in the scales of the $y$-axes in the 2 data sets (n.s.: no significant difference in invertebrate density between years; ${ }^{*} \mathrm{p}<0.05$;

$$
\left.{ }^{* *} \mathrm{p}<0.01\right)
$$

zone. In particular, A. ater decreased from 18529 (5905 SD) to 514 (367 SD) individuals $\mathrm{m}^{-2}$.

Sample-based rarefaction curves reached a plateau only in the Porphyra zone in 2001 (Fig. 3). Chao 2 estimates of total species richness showed a significant decline in the Porphyra zone in 2001, with increases in the Ulva and Granularis zones (based on the lack of overlapping confidence intervals; Fig. 4). No significant changes in total species richness were detected in the 3 zones lowest on the shore.

The communities in all 6 zones changed significantly between 1980 and 2001, even when the contribution made by Mytilus galloprovincialis was excluded (ANOSIM, p < 0.01; Fig. 5). In the Porphyra zone, $90 \%$ of the average difference between these 2 groups was accounted for by a decrease in the abundance of 1 species, the isopod Exosphaeroma varicolor. Over the same period, the Ulva and Granularis zones, respectively, had average community dissimilarities of 86.4 and $99.8 \%$. In both zones, this difference was explained primarily by increased densities of the nudibranch Onchidella capensis. In the Gigartina zone, the small gastropods Aetoniella nigra and Tricolia neritina contributed the most to the $93.7 \%$ dissimilarity between years. Both species were abundant in 1980 (mean densities of $14771 \mathrm{~m}^{-2}$ [6107 SD] and $5729 \mathrm{~m}^{-2}$ [2758 SD], respectively), but were absent in 2001. Within the Aulacomya zone, Aulacomya ater, which decreased dramatically between 1980 and 2001, contributed most to the $96.8 \%$ dissimilarity between the pre- and post-invasion communities. Similarly, community differences in the Choromytilus zone were explained primarily by the replacement of Choromytilus meridionalis by M. galloprovincialis.

\section{DISCUSSION}

The role of mussels as dominant species affecting community structure of benthic intertidal habitats is well established (Petraitis 1995, Tokeshi \& Romero 1995, Enderlein \& Wahl 2004, Miyamoto \& Noda 2004). Mussels play a regulating role in community structure in 3 ways. Firstly, through their monopolisation of primary rock space (Ruiz Sebastián et al. 2002, Steffani \& Branch 2003b), secondly, by providing secondary habitat in the form of a 3-dimensional matrix (which provides habitat for other species and may enhance their recruitment; Crooks \& Khim 1999, Miyamoto \& Noda 2004), and thirdly, through their biological activities (e.g. by filter-feeding they remove large quantities of particulate matter and plankton from near-shore waters, reducing larval settlement of some associated species; Tsuchiya \& Nishihira 1986, Asmus \& Asmus 1991). The structural complexity of mussel beds provides a multitude of microhabitats that ameliorate fluctuating environmental conditions and offer protection from predation (Dumas \& Witman 1993). Thus, it is not surprising that the intertidal fauna on Marcus Island changed considerably following the arrival of the invasive mussel Mytilus galloprovincialis.

As invasions by marine alien species are to a large extent unpredictable, it is exceptionally difficult to assess the impact of these species through replicated experimental manipulations. As such, this study makes use of data collected at a single point in time in 1980 (prior to the invasion of Mytilus galloprovincialis) in order to make comparisons with post-invasion communities. This pre-invasion data, however, has limitations that govern the extent of the current comparison. Firstly, no data on the algal component of the intertidal community were collected. Secondly, no measure of biomass was made for any species. Thirdly, no assessment was made of open rock space, and, lastly, a small number of samples were collected. In order to assess the adequacy of our sample size, rarefied species accumulation curves were constructed. Only in the Por- 
a

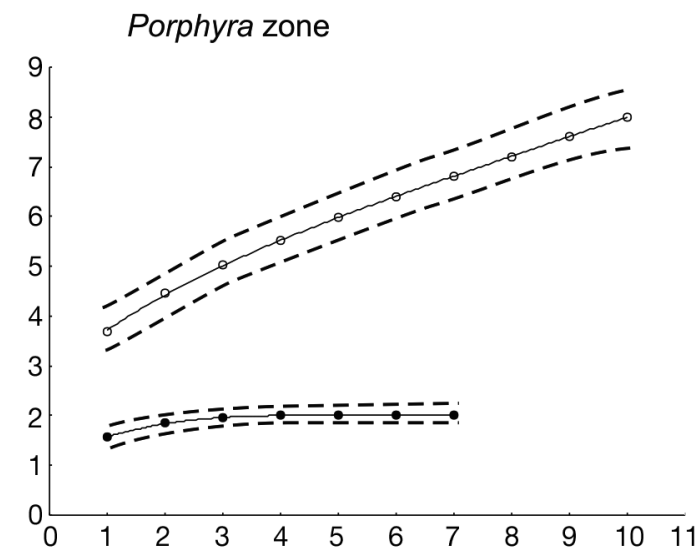

C

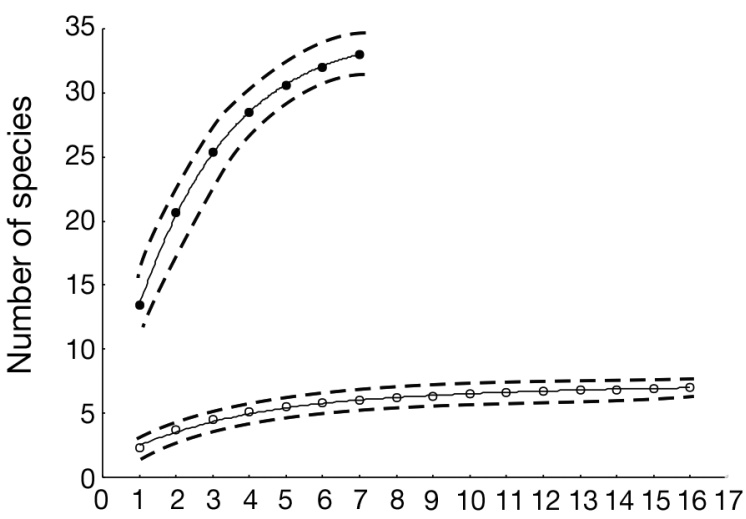

e Aulacomya zone

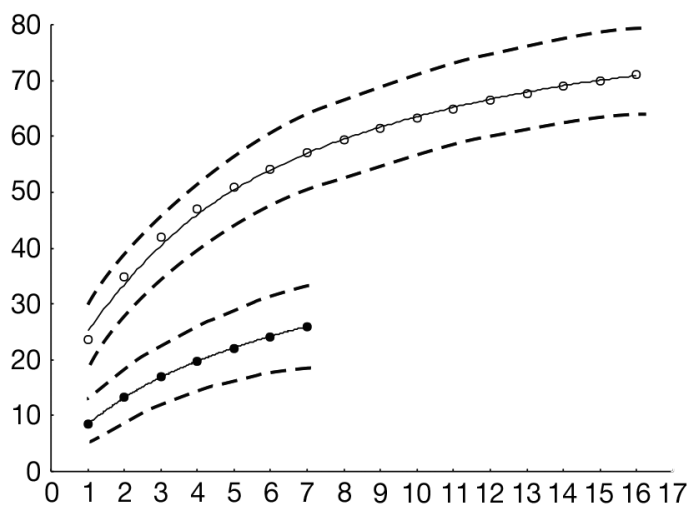

b

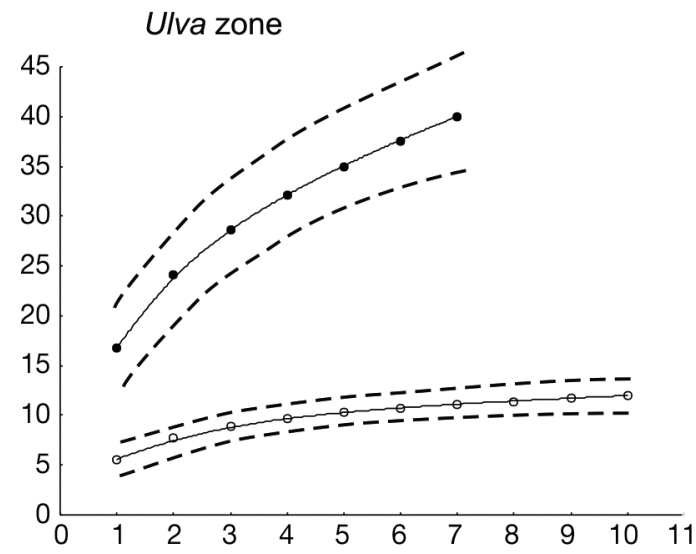

d
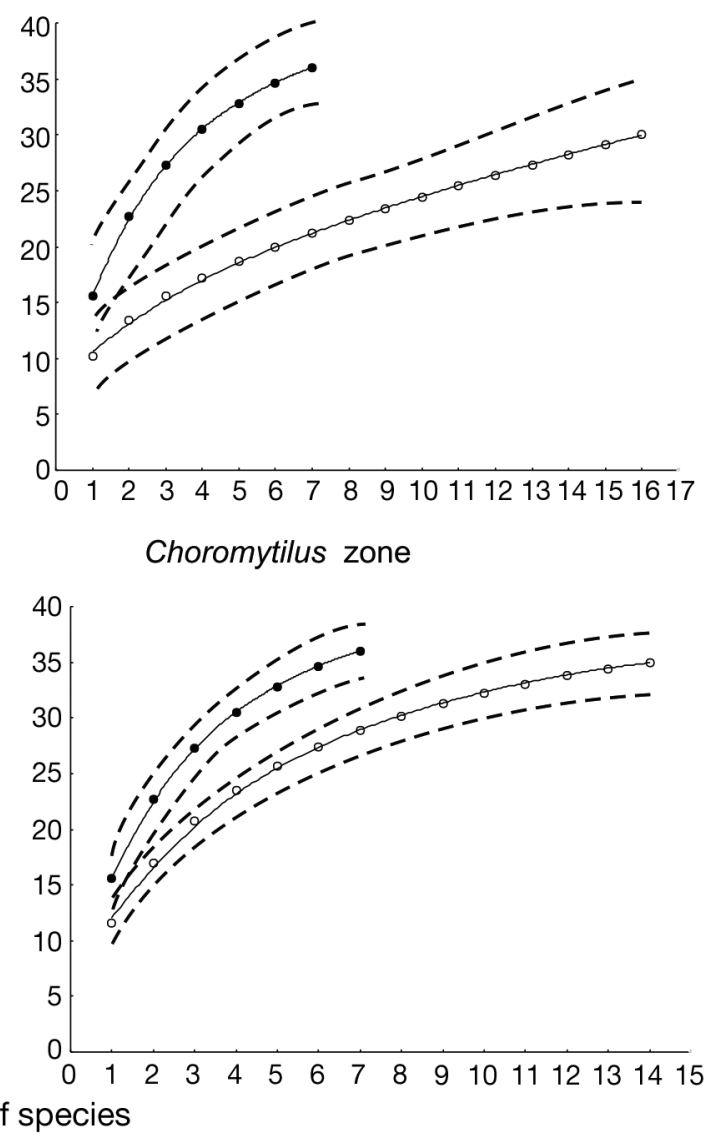

Fig. 3. Sample-based rarefaction species curves with 95\% confidence intervals for all sampling zones in 1980 (○) and $2001(\bullet)$

phyra zone in 2001 was an asymptote reached, indicating that the sampling effort was too low to fully characterise species composition. However, the Chao 2 incidence-based richness estimate is still considered an appropriate measure of total diversity as it usually requires ca. $50 \%$ of species to be sampled (Colwell \& Coddington 1994). As no long-term continuous monitoring has taken place on Marcus Island, it is not possible to unequivocally ascribe the observed community changes solely to the invasion of $M$. galloprovincialis. Nonetheless, inter-annual changes of species richness and abundance within the benthic communities of Saldanha Bay (in which Marcus Island is located) are known to be minimal (Jackson \& McGibbon 1991), and it is likely that a similar pattern applies to intertidal communities.

The Mytilus galloprovincialis invasion affected the indigenous mussels Aulacomya ater and Choromytilus 

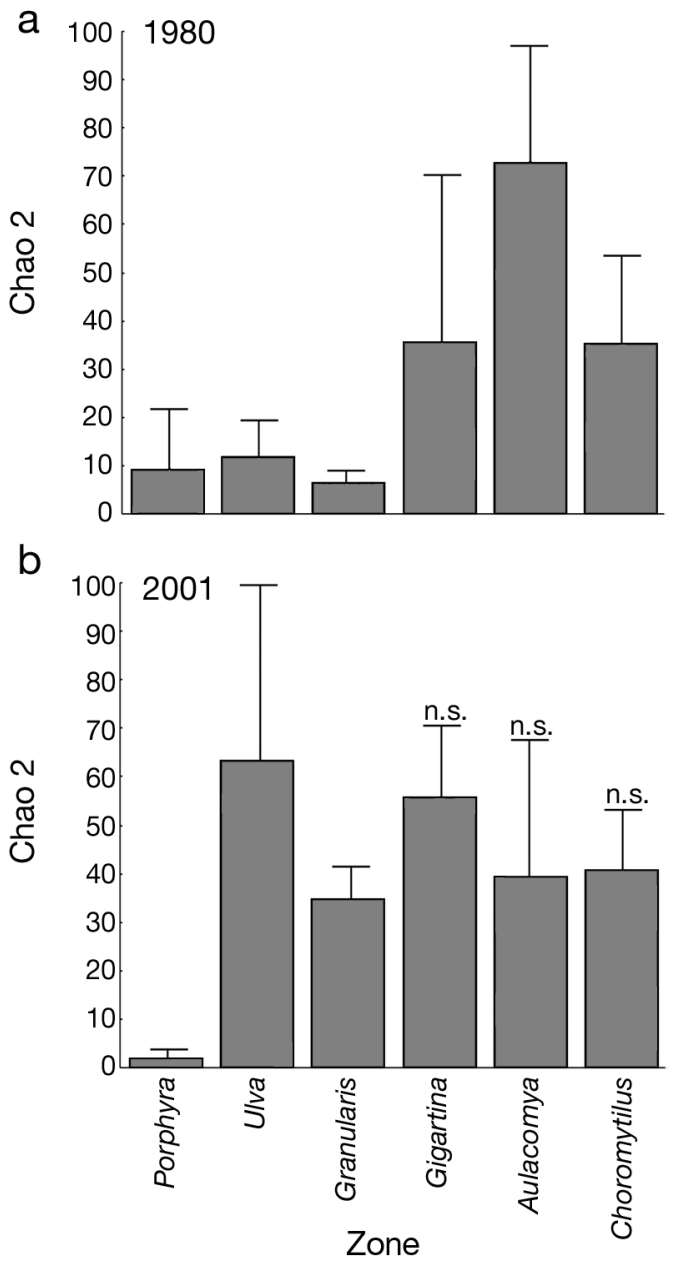

Fig. 4. Chao 2 estimates (+95\% confidence intervals) for all sampling zones on Marcus Island in 1980 and 2001 (n.s.: no significant difference based on overlapping confidence intervals)

meridionalis in several ways. In the low-shore (Aulacomya zone), the density of $A$. ater decreased by almost 2 orders of magnitude as this slow-growing species was outcompeted by $M$. galloprovincialis. There was also a decrease in the overall density of mussels in this zone, as the small $A$. ater has been largely replaced by the larger $M$. galloprovincialis. In the high- to mid-shore, densities of $A$. ater increased dramatically as protection provided by $M$. galloprovincialis beds enabled this species to survive high on the shore, from where it was precluded previously by virtue of its intolerance to desiccation (Van Erkom Schurink \& Griffiths 1990), although it was still numerically far subordinate. The most striking impact of the M. galloprovincialis invasion was the total replacement of C. meridionalis in both the Aulacomya and Choromytilus zones and, to a lesser extent in the Gigartina zone (Fig. 1). It should, however, be noted that C. meridionalis still thrives in substantial subtidal stocks and often occupies heavily silted and sandy areas among rocks (T. B. Robinson pers. obs.), both habitats rarely occupied by $M$. galloprovincialis along the South African coast. Due to the presence of these refuges, it is highly unlikely that $C$. meridionalis will be driven to local extinction by the appearance of M. galloprovincialis.

The change in community structure in the Porphyra zone is unlikely to be a consequence of the mussel invasion, as Mytilus galloprovincialis does not occur this high on the shore. Crustacea and insect larvae dominated in both 1980 and 2001, and minor changes in abundance of these taxa probably result from seasonal variation in abundance of the dominant alga Porphyra capensis (Griffin et al. 1999).

Prior to the arrival of Mytilus galloprovincialis, both the Ulva and Granularis zones were patchy environments, comprising mainly bare rock interspersed with patches of algae and large limpets. These zones were therefore spatially simple habitats in which physical stress would have played an important role in determining biological assemblages. However, following the mussel invasion, the patchy mosaic of bare rock, algae and limpets was transformed to a less patchy but structurally more complex mussel matrix. Reduced patchiness in the Granularis zone is reflected in the reduction in sample variability from 1980 to 2001 (Fig. 5). Thus, the physical stresses previously typical of these zones were ameliorated, and the nature of the habitat in these zones was dramatically altered. This accounts for the massive increase in invertebrate density, total species richness, as well as the changes in community composition recorded in these zones.

In the Gigartina zone, the density of mussels remained unaltered, despite changes in the species composition (Fig. 1). However, unlike the indigenous mussels, Mytilus galloprovincialis develops multi-layered beds (Hockey \& Van Erkom Schurink 1992, McQuaid \& Phillips 2000). Consequently, the invasion has resulted in an increase in structural complexity in this zone. Despite this change, total species richness remained unaltered. This is in line with findings by Hammond (2001) who recorded no difference in infaunal species diversity between indigenous mussels and M. galloprovincialis. The substantial decrease in the invertebrate density was due to extreme reductions in the number of gastropods Aetoniella nigra and Tricolia neritina, although it remains unclear whether these decreases are a consequence of natural variation, or reflect changes induced by the arrival of $M$. galloprovincialis.

Because the Aulacomya zone was previously characterised by the presence of mussel beds, the invasion of Mytilus galloprovincialis is unlikely to have altered the uniformity of the habitat in this zone to any great 
a

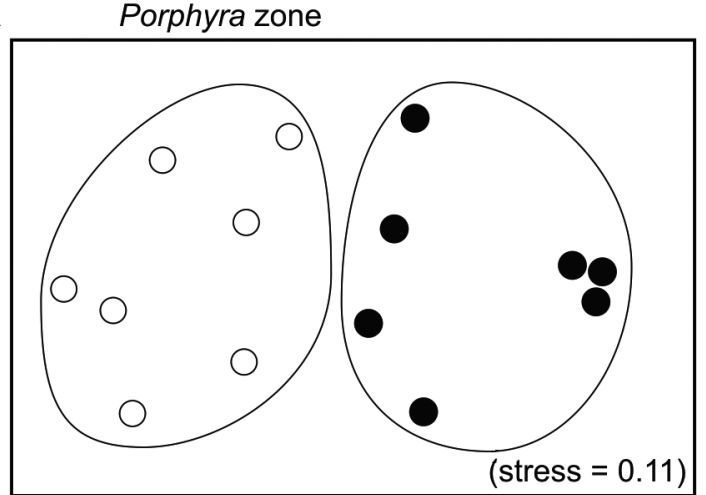

c

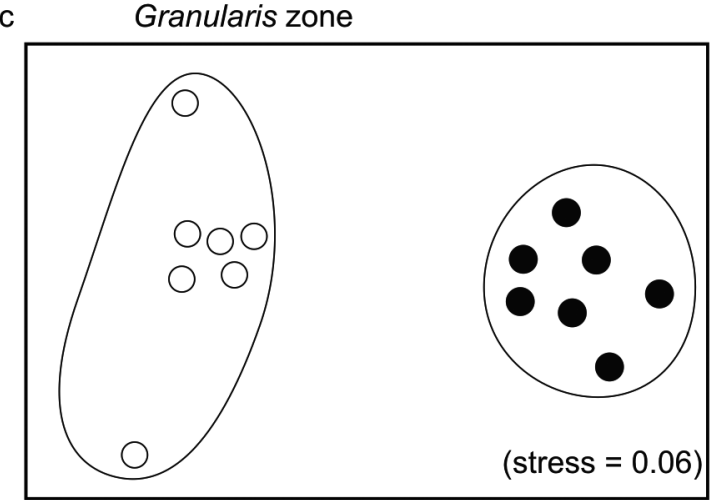

e

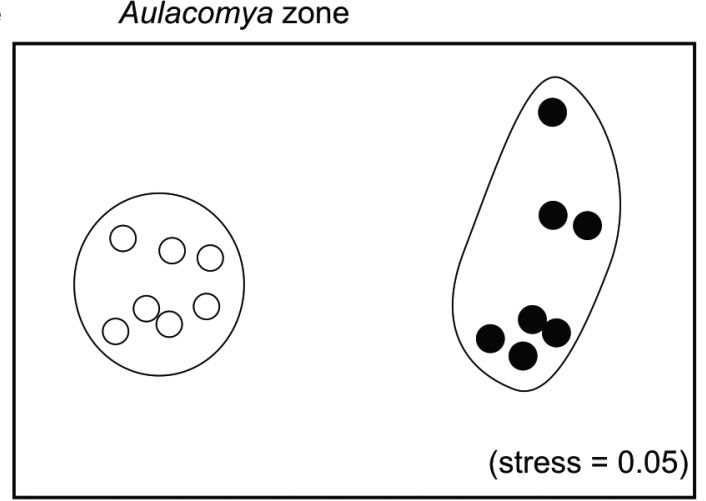

b

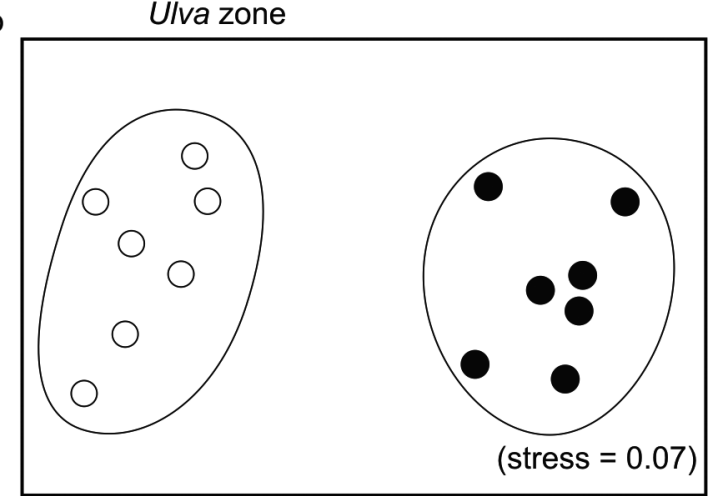

d

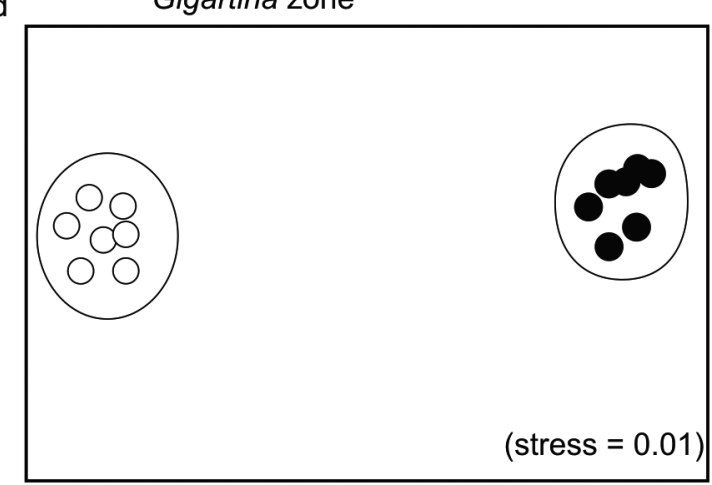

f

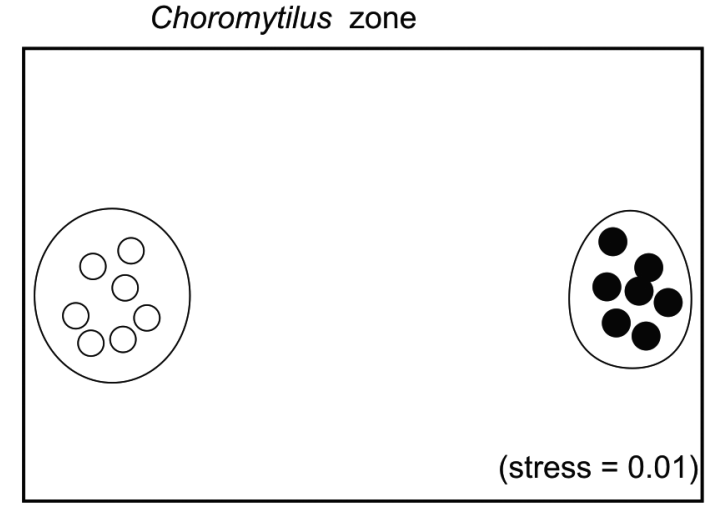

Fig. 5. Non-metric multidimensional scaling of species abundance (fourth-root transformed) for all 6 sampling zones (a) to (f) in 1980 (O) and $2001(\mathbf{0})$, excluding the contribution made by Mytilus galloprovincialis

extent. However, Aulacomya ater decreased considerably in density between 1980 and 2001 (from 18529 to 514 individuals $\mathrm{m}^{-2}$ ), while $M$. galloprovincialis conversely increased. The switch from mono-layered beds of small mussels to multilayered beds of large mussels resulted in a significant reduction in the overall density of mussels present in this zone. Van Erkom Schurink \& Griffiths (1990) reported a density of 10000 A. ater $\mathrm{m}^{-2}$ in this zone at Marcus Island. Thus, it would appear that $A$. ater has decreased progressively in abundance at Marcus Island since the arrival of M. galloprovincialis. The poor competitive ability of A. ater (relative to M. galloprovincialis) is thought to be a consequence of its relatively slow growth rate (Hockey \& Van Erkom Schurink 1992, Van Erkom Schurink \& Griffiths 1993).

The Choromytilus zone was originally characterised by substantial beds of this indigenous mussel. The arrival of Mytilus galloprovincialis, thus, did not replace the type of habitat present, but altered it from a singlelayered mussel bed, typical of Choromytilus meridionalis, to a multi-layered mussel matrix associated with M. galloprovincialis (Griffiths et al. 1992). As a result, no change was recorded in total species richness. The fact that $M$. galloprovincialis reached its highest densities in this lower-most zone is unexpected, as the den- 
sity of this species on South African shores is generally accepted to be maximal in the mid-intertidal zone (Van Erkom Schurink \& Griffiths 1990).

In conclusion, the biological impacts of the Mytilus galloprovincialis invasion on intertidal invertebrate communities were linked to 3 key elements and were not evenly spread across the shore. Firstly, physical stress in the mid- to high-shore zones was ameliorated by the presence of M. galloprovincialis. Secondly, habitat complexity was increased in zones where M. galloprovincialis replaced bare rock or biota that provided a physically less complex secondary habitat. Thirdly, patchiness was reduced, at least in the Granularis zone.

Mytilus galloprovincialis is an aggressive invader, and, apart from exhibiting strong competitive interactions with other species along the South African coast (Branch \& Steffani 2004, Robinson et al. 2005), it has also resulted in striking direct and indirect changes to the invertebrate community structure of rocky-shores.

Acknowledgements. We thank the National Research Foundation, Marine and Coastal Management, the Mellon Foundation, the Marine Biology Research Institute (University of Cape Town) and the Centre for Invasion Biology (University of Cape Town) for funding this project.

\section{LITERATURE CITED}

Asmus RM, Asmus H (1991) Mussel beds: Limiting or promoting phytoplankton? J Exp Mar Biol Ecol 148:215-232

Bachelet G, Simon-Bouhet B, Desclaux C, Gracia-Meunier P and 6 others (2004) Invasion of the eastern Bay of Biscay by the nassariid gastropod Cyclope neritea: origin and effects on resident fauna. Mar Ecol Prog Ser 276:147-159

Berman J, Carlton JT (1991) Marine invasion processes: interactions between native and introduced marsh snails. J Exp Mar Biol Ecol 150:267-281

Branch GM, Steffani CN (2004) Can we predict the effects of alien species? A case-history of the invasion of South Africa by Mytilus galloprovincialis (Lamarck). J Exp Mar Biol Ecol 300:189-215

Byers JE (2000) Competition between two estuarine snails: implications for invasions of exotic species. Ecology 81:1225-1239

Byrnes J, Witman JD (2003) Impact assessment of an invasive flatworm, Convoluta convoluta, in the southern Gulf of Maine. J Exp Mar Biol Ecol 293:173-191

Chao A (1987) Estimating the population size for capturerecapture data with unequal catchability. Biometrics 43: 783-791

Colwell RK (2005) EstimateS: statistical estimation of species richness and shared species from samples, Version 7.5. User's guide and application. Available at http://purl.oclc.org/estimates

Colwell RK, Coddington JA (1994) Estimating terrestrial biodiversity through extrapolation. Philos Trans R Soc Lond Ser B 345:101-118

Crooks JA, Khim HS (1999) Architectural vs biological effects of a habitat-altering, exotic mussel, Musculista senhousia. J Exp Mar Biol Ecol 240:53-75

Dumas JV, Witman JD (1993) Predation by herring gulls (Larus argentatus Coues) on two rocky intertidal crab spe- cies (Carcinus maenas (L.) \& Cancer irroratus Say). J Exp Mar Biol Ecol 169:89-101

Enderlein P, Wahl M (2004) Dominance of blue mussels versus consumer-mediated enhancement of benthic diversity. J Sea Res 51:145-155

Gosselin LA, Chia F (1995) Distribution and dispersal of early juvenile snails: effectiveness of intertidal microhabitats as refuges and food sources. Mar Ecol Prog Ser 128: 213-223

Gotelli N, Colwell RK (2001) Quantifying biodiversity: procedures and pitfalls in the measurement and comparison of species richness. Ecol Lett 4:379-391

Griffin NJ, Bolton JJ, Anderson RJ (1999) Distribution and population dynamics of Porphyra (Bangailes, Rhodophyta) in the southern Western Cape, South Africa. J Appl Phycol 11: $429-436$

Griffiths CL, Hockey PAR, Van Erkom Schurink C, Le Roux PJ (1992) Marine invasive aliens on South African shores: implications for community structure and trophic functioning. S Afr J Mar Sci 12:713-722

Grosholz ED (2002) Ecological and evolutionary consequences of coastal invasions. Trends Ecol Evol 17:22-27

Hammond W (2001) Factors affecting the infauna associated with mussel beds. MSc thesis, University of Cape Town

Harris JM, Branch GM, Elliott BL, Currie B, Dye AH, McQuaid CD, Tomalin BJ, Velasquez C (1998) Spatial and temporal variability in recruitment of intertidal mussels around the coast of southern Africa. S Afr J Zool 33:1-11

Hockey PAR, Van Erkom Schurink C (1992) The invasive biology of the mussel Mytilus galloprovincialis on the southern African coast. Trans R Soc S Afr 48:123-139

Jackson LF, McGibbon S (1991) Human activities and factors affecting the distribution of macrobenthic fauna in Saldanha Bay. S Afr J Aquat Sci 17:89-102

Le Pape O, Guerault D, Desaunay Y (2004) Effect of an invasive mollusk, American slipper limpet Crepidula fornicata, on habitat suitability for juvenile common sole Solea solea in the Bay of Biscay. Mar Ecol Prog Ser 277:107-115

Mack RN, Simberloff D, Lonsdale WM, Evans H, Clout M, Bazzaz FA (2000) Biotic invasions: causes, epidemiology, global consequences, and control. Ecol Appl 10:689-710

McQuaid CD, Phillips TE (2000) Limited wind-driven dispersal of intertidal mussel larvae: in situ evidence from the plankton and the spread of the invasive species Mytilus galloprovincialis in South Africa. Mar Ecol Prog Ser 201: 211-220

Miyamoto Y, Noda T (2004) Effects of mussels on competitively inferior species: competitive exclusion to facilitation. Mar Ecol Prog Ser 276:293-298

Occhipinti-Ambrogi A, Savini D (2003) Biological invasions as a component of global change in stressed marine ecosystems. Mar Pollut Bull 46:542-551

Petraitis PS (1995) The role of growth in maintaining spatial dominance by mussels (Mytilus edulis). Ecology 76: $1337-1346$

Robinson TB, Griffiths CL, McQuaid CD, Rius M (2005) Marine alien species of South Africa - status and impacts. Afr J Mar Sci 27:297-306

Ruiz GM, Fofonoff P, Hines AH, Grosholz ED (1999) Nonindigenous species as stressors in estuarine and marine communities: assessing invasion impacts and interactions. Limnol Oceanogr 44:950-972

Ruiz Sebastián C, Steffani CN, Branch GM (2002) Homing and movement patterns of a South African limpet Scutellastra argenvillei in an area invaded by an alien mussel Mytilus galloprovincialis. Mar Ecol Prog Ser 243:111-122 Seed R, Suchanek TH (1992) Population and community ecol- 
ogy of Mytilus. In: Gosling E (ed) The mussel Mytilus: ecology, physiology, genetics and culture. Elsevier, New York Steffani CN, Branch GM (2003a) Spatial comparisons of populations of an indigenous limpet Scutellastra argenvillei and an alien mussel Mytilus galloprovincialis along a gradient of wave energy. Afr J Mar Sci 25:195-212

Steffani CN, Branch GM (2003b) Temporal changes in an interaction between an indigenous limpet Scutellastra argenvillei and an alien mussel Mytilus galloprovincialis: effects of wave exposure. Afr J Mar Sci 25:213-229

Tokeshi M, Romero L (1995) Filling a gap: dynamics of space occupancy on a mussel dominated subtropical rocky shore.

Editorial responsibility: Steven Morgan (Contributing Editor), Bodega Bay, California, USA
Mar Ecol Prog Ser 119:167-176

Tsuchiya M, Nishihira M (1986) Islands of Mytilus edulis as a habitat for small intertidal animals: effect of Mytilus age structure on the species composition of the associated fauna and community organization. Mar Ecol Prog Ser 31: $171-178$

Van Erkom Schurink C, Griffiths CL (1990) Marine mussels of southern Africa-their distribution patterns, standing stocks, exploitation and culture. J Shellfish Res 9:75-85

Van Erkom Schurink C, Griffiths CL (1993) Factors affecting relative rates of growth in four South African mussel species. Aquaculture 109:257-273

Submitted: May 3, 2006; Accepted: December 1, 2006

Proofs received from author(s): May 28, 2007 